\begin{tabular}{|l|l|l|}
\hline \multicolumn{2}{|c|}{ PublisherInfo } \\
\hline \hline PublisherName & $:$ & BioMed Central \\
\hline \hline PublisherLocation & $:$ & London \\
\hline \hline PublisherImprintName & $:$ & BioMed Central \\
\hline \hline
\end{tabular}

\title{
BRCA1 linked with Fanconi anemia
}

\begin{tabular}{|l|l|l||}
\hline \multicolumn{2}{|c|}{ ArticleInfo } \\
\hline \hline ArticleID & $:$ & 3919 \\
\hline \hline ArticleDOI & $:$ & $10.1186 /$ gb-2001-2-5-reports0014 \\
\hline \hline ArticleCitationID & $:$ & reports0014 \\
\hline \hline ArticleSequenceNumber & $:$ & 16 \\
\hline \hline ArticleCategory & $:$ & Paper report \\
\hline \hline ArticleFirstPage & $:$ & 1 \\
\hline \hline ArticleLastPage & $:$ & 4 \\
\hline \hline & & RegistrationDate : 2001-4-9 \\
ArticleHistory & $:$ & Received \\
\hline ArticleCopyright & $:$ & BioMed Central Ltd2001 \\
\hline \hline ArticleGrants & $:$ & \\
\hline \hline
\end{tabular}




\begin{tabular}{|l|l|l||}
\hline ArticleContext & $:$ & 130592255 \\
\hline
\end{tabular}

\section{Cathy Holding}

\section{Abstract}

Fanconi anemia and breast cancer have been shown to share a common DNA repair pathway.

\section{Significance and context}

The breast cancer susceptibility protein BRCA1 and the many proteins involved in the hereditary blood disorder Fanconi anemia (FA) function in a common cellular pathway regulating DNA repair, according to Garcia-Higuera et al. Complementation studies have shown that mutations in several different genes can be responsible for FA, but FANCA, FANCC, FANCF and FANCG proteins all appear to be associated with the assembly of a multisubunit complex that normally functions in response to DNA damage. Loss of activity of this complex, due either to its failure to assemble or to failure of components upstream or downstream of the functional complex, results in the different phenotypes of FA. By investigating the role of $F A N C D 2$, the latest gene shown to be linked to FA, Garcia-Higuera et $a l$. have also uncovered an unsuspected role for BRCA1 in this disease, demonstrating for the first time a connection between two previously unconnected diseases.

\section{Key results}

Using normal and FA-derived cell lines, Garcia-Higuera et al. systematically explored the interaction of the various components governing the assembly or function of the multisubunit complex. They found that a short and a longer version of the FANCD2 protein are present in normal cells, and that the longer version seems to appear in response to DNA damage. In almost all FA cell lines, however, the longer version of FANCD2 failed to appear, coincident with failure of the multisubunit complex to assemble and with sensitivity in these cell lines to DNA damage. Supplementing the mutant cDNA in the various cell lines with normal protein encoded by a transfected cDNA resulted in the reappearance of the multisubunit complex together with the longer version of FANCD2 and recovery of resistance to DNA damage. The authors reasoned that FANCD2 must have been modified by the action of the multisubunit complex, and that the levels of the modified protein rise in response to DNA damage. They showed that the modification involved the addition of a single ubiquitin molecule and that following ionizing radiation damage, these modified proteins appeared in nuclear aggregates that also contained the BRCA1 protein. Garcia-Higuera et al. then looked at the role of BRCA1 in relation to the FA multisubunit complex. In a cell line that expressed only truncated BRCA1, DNA damage did not result 
in the usual increase in the level of modified FANCD2 protein and no nuclear aggregates appeared. They therefore reasoned that BRCA1 must be involved in organizing the mono-ubiquitinated proteins into the nuclear aggregates and that some kind of functional interaction between the two proteins must occur. They found that the aggregates also form during cell division and have a role in synaptonemal complexes of meiotic chromosomes.

\section{Conclusions}

Garcia-Higuera et al.propose that the FANCD2 protein is mono-ubiquitinated by the FA multisubunit complex at specific times during cell division or following DNA damage. This acts as a targeting signal for FANCD2, and BRCA1 causes relocalization of these modified proteins into nuclear aggregates with BRCA1 itself and possibly with other proteins involved in DNA repair. After use, FANCD2 is deubiquitinated to the shorter form, disaggregated from BRCA1 and recycled back into the nuclear compartment.

\section{Reporter's comments}

This is the first demonstration that all the cloned FA genes and BRCA1 interact in a common pathway of DNA repair. The authors conclude that disruption of this pathway, by inherited or acquired mutation of any of these genes, leads to a cancer risk.

\section{Table of links}

Molecular Cell

\section{References}


1. Garcia-Higuera I, Taniguchi T, Ganesan S, Maey MS, Timmers C, Hejna J, Grompe M, D'Andrea AD: Interaction on the Fanconi anemia proteins and BRCA1 in a common pathway. Mol Cell. 2001, 7 : 249-262. 1097-4164

This PDF file was created after publication. 